\title{
Pharmacovigilance in Neuroscience
}

\section{Farmacovigilancia en neurociencia}

\author{
María-Pilar Sánchez-de-Paz ${ }^{2}$ \\ Gustavo Da-Prat-de-Magalhaes ${ }^{1}$ \\ Santiago Isa ${ }^{1}$ \\ Victoria Aldinio ${ }^{1}$ \\ Andres-Norberto Latella ${ }^{2}$ \\ Emilia-Mabel Gatto ${ }^{1}$ \\ Galeno J. Rojas ${ }^{12}$
}

How to cite this article:

Sánchez-de-Paz, M.; Da-Prat-de-Magallanes, G.; Isa, S.; Aldinio, V.; Latella, A.; Gatto, E. \& Rojas, G. J. (2021). Pharmacovigilance in Neuroscience. Journal of Applied Cognitive Neuroscience, 2(1), e00163800.

https://doi.org/10.17981/JACN.2.1.2021.04

Manuscript received on 7th April 2021 Accepted on 8th June 2021

\begin{abstract}
Adverse Drug Reactions (ADRs) have a high impact on morbidity and mortality of the population, becoming a public health issue. Studying and publishing about these is referred as pharmacovigilance.

The primary objective of this article is to describe and compare the adverse reactions produced by drugs of nervous system action (CNS-D) and neurological ADRs produced by drugs of systemic action (Sys-D). To further develop the need of reporting adverse reactions.

This is an observational, cross-sectional, retrospective study performed on a database of neurological consultations which took place at the Neurology department. Patients meeting the inclusion criteria were selected and divided into two groups: Sys-D and CNS-D. Demographic and neurological variables were analyzed. Parametric and non-parametric statistics were used according to distribution. The Naranjo Algorithm (NA) was used to define causality.

71 ADRs were described, from which $63.38 \%(n=45)$ were produced by CNS-D, especially antiepileptics by $47 \%(n=21)$ and psycholeptics by $44 \%$. Of the total, $36.62 \%(n=26)$ were caused by Sys-D, such as antineoplastics $(n=9)$ and antibiotics $(n=9)$, being Cefepime the most frequent. The diagnosis of ADRs caused by a Sys-D was delayed prolonging hospitalization ( $p$ 0.05) due to a lower NA score (p 0.003) compared to the CNS-D group.

Multiple frequently used drugs of systemic action, such as antineoplastics and antibiotics, generate neurological adverse effects. From our analysis, it was presumed that the suspicion of a neurological ADR caused by these drugs was scarce, thus causing a higher morbidity for the patient.
\end{abstract}

Keywords: Pharmacovigilance; Epidemiology; Adverse reactions; Drugs; Neurology; Pharmacology

\section{Resumen}

Las Reacciones Adversas a Medicamentos (RAM) tienen un alto impacto en la morbilidad y mortalidad de la población, convirtiéndose en un problema de salud pública. El estudio y la publicación de las mismas se denomina farmacovigilancia. El objetivo principal de este artículo es describir y comparar las reacciones adversas producidas por medicamentos de acción sobre el sistema nervioso (SNC-D) y las RAM neurológicas producidas por medicamentos de acción sistémica (Sys-D). Profundizar en la necesidad de notificar las reacciones adversas.

Es un estudio observacional, transversal y retrospectivo realizado sobre una base de datos de consultas neurológicas que tuvieron lugar en el servicio de Neurología. Se seleccionaron los pacientes que cumplían los criterios de inclusión y se dividieron en dos grupos: Sys-D y CNS-D. Se analizaron variables demográficas y neurológicas. Se utilizó estadística paramétrica y no paramétrica según la distribución. Se utilizó el Algoritmo de Naranjo (NA) para definir la causalidad.

Se describieron 71 RAM, de las cuales el 63,38\% $(n=45)$ fueron producidas por SNC-D, especialmente antiepilépticos en un $47 \%(n=21)$ y psicolépticos en un $44 \%$. Del total, el $36,62 \%(n=26)$ fueron causadas por Sys-D, como antineoplásicos $(n=9)$ y antibióticos $(n=9)$, siendo la Cefepime la más frecuente. El diagnóstico de las RAM causadas por un Sys-D se retrasó prolongando la hospitalización (p 0,05) debido a una menor puntuación de NA (p 0.003) en comparación con el grupo de SNC-D. Múltiples fármacos de acción sistémica frecuentemente utilizados, como los antineoplásicos y los antibióticos, generan efectos adversos neurológicos. A partir de nuestro análisis, se presume que la sospecha de una RAM neurológica causada por estos fármacos es escasa, provocando así una mayor morbilidad para el paciente.

Palabras clave: Farmacovigilancia; Epidemiología; Reacciones adversas; Fármacos; Neurología; Farmacología

${ }^{1}$ Department of Neurology, Sanatorio de la Trinidad Mitre, Buenos Aires, Argentina.

Contact mail: pilasdp@gmail.com

${ }^{2}$ Department of Pharmacology, Universidad de Buenos Aires, Argentina. 


\section{INTRODUCTION}

Pharmacovigilance $(\mathrm{PhV})$ is defined by the World Health Organization (WHO) as the science and activities related to the detection, assessment, understanding and prevention of adverse effects or any other drug-related problem (World Health Organization-WHO/ The Uppsala Monitoring Centre, 2001). It was developed on the early ' 60 s, after the use of Thalidomide in pregnant women, whose newborns had malformations (WHO, 2001; Regulation No. 5358, 2012).

In 1964, the Instituto Nacional de Farmacología y Bromatología was created in Argentina. After several changes, in September 1993 the Pharmacovigilance National System was founded, as well as the ANMAT (Administración Nacional de Medicamentos, Alimentos y Tecnología Médica). In 1994, Argentina got into the monitoring system of WHO, which receives the alerts and signs of adverse effects, thus becoming the first country in Latin America to be a member of Uppsalla Monitoring Centre (Bignone \& Schiaffino, 2016; WHO, 1999).

WHO defines Adverse Drug Reaction (ADR) as "a response to a drug which is noxious and unintended, and which occurs at doses normally used in humans for prophylaxis, diagnosis, or treatment of a disease, or to modify any biological function" (Regulation No. $5358,2012)$. ADRs represent a high impact on morbidity and mortality of the population causing a problem to public health (Bignone \& Schiaffino, 2016; Ponte, Ragusa, Armenteros \& Wachs, 2013). Adverse reactions are estimated to be between the fourth and sixth cause of mortality (Bignone \& Schiaffino, 2016; Regulation No. 5358, 2012; Lazarou, Pomeranz, \& Corey, 1998).

According to different international publications, between $15 \%$ and $24 \%$ of hospitalized patients show adverse effects, and up to $15 \%$ of them are admitted because of adverse drug effects (Bignone \& Schiaffino, 2016). In two meta-analysis carried out in the USA and in Australia, the incidence of ADR varied from $4.4 \%$ to $5.8 \%$ and $5.2 \%$ to $8.2 \%$ respectively. In Brazil, Camargo, Cardozo ,Ferreira and Heineck (cited by Chaio, Toibaro, Valicenti \& Saidón, 2013) demonstrated that $43 \%$ of hospitalized patients showed adverse reactions. Likewise, meta-analysis done by Lazarou et al. (1998), not only demonstrated the high incidence rate of adverse effects in hospitalized patients, but also that $6.7 \%$ showed serious ADR. In Argentina, Chaio et al. (2013) demonstrated an incidence rate of $36 \%$ of ADR in hospitalized patients being this the cause of $11 \%$ of the admissions.

The great variability of incidence rates among the different publications could be due to their design (Chaio et al., 2013). Information regarding the frecuency of ADR is scarce in the commercialization phase in our country (Bignone \& Schiaffino, 2016). Notification of the ADR by the different medicine related agencies plays an important role on PhVG (Regulation No. 5358, 2012).

Multiple factors influence the increase of ADR incidence rates. Some of them are the increase in life expectancy and the development of new medicines, among others (Bignone \& Schiaffino, 2016). Elderly people, newborns and polypharmacy patients are more vulnerable to develop them. It is common for patients over 65 years old to have comorbidities leading to polypharmacy associated to pharmacokinetics and pharmacodynamics changes, increasing the risk of ADR (Ponte et al., 2013; Rattagan et al. 2016). Moreover, mistakes 
in prescription, unawareness of drug interactions and self-medication influence ARD incidence (Bignone \& Schiaffino, 2016; Orta, Garcia, Triolet, Gómez \& Ruiz, 2008).

From the neurological point of view, neurologists usually prescribe drugs with nervous system mechanism of action (CNS-D), with further knowledge of their ADR. It is important to underline that patients with neurological disorders have more risk in developing neurological ADR (Sauro, Quan, Sikdar, Faris \& Jette, 2017). In addition, studies carried out by Rattagan et al. (2016) and Rojas, Demey and Arizaga (2013) evidenced an irrational use of psychotropic medications in the country, especially benzodiazepines. This has not only extended the admission days of the patients, who are exposed to an increase of intrahospital complications, but also $21.2 \%$ of the patients did not have indications for psychotropics.

With the development of new pharmacological therapies, neurologists face different ADR with neurological symptoms that are generated by systemic drugs, such as antibiotics, immunosupressants, anti-inflammatories, etc. Since there is limited knowledge of long-term ADR, some of them might be taken for primary neurological diseases. Many factors of drug metabolism can increase the susceptibility of neurotoxicity, such as the nutritional status, cerebral blood flow, permeability of the blood-brain barrier, routes of administration, the pharmacokinetics of the drug and its metabolites (Grill \& Maganti, 2011).

As above mentioned, the primary objective of this article is to describe and analyze the pharmacological adverse reactions in the neurological clinical practice. As for secondary objectives, discriminate those ADR produced by drugs used for the treatment of diseases of the Central Nervous System (CNS-D) and the ADRs related to the nervous system engagement provoked by Systemic Drugs (Sys-D), naming both situations as "Neuro-PharmacoVigilance" (NPhVG). Compare different characteristics of ADRs between these two groups. And develop the need for adverse reaction's notification.

\section{Materials And Methods}

A cross-sectional retrospective observational study was conducted over the database regarding in-patient and outpatient clinic of our Department of Neurology between the 1st July 2005 and 1st July 2017. The search of clinical histories was carried out and the required information was analyzed to collect the data in special worksheets. These included personal data (age, gender, nationality, scholarship), admission data (date of entry and exit, reason for hospitalization, admission in a general ward or critical care unit), adverse drug reaction (type, Naranjo score, severity, re-exposure, notification, beginning and ending of symptoms), background and usual medication of the patient.

As inclusion criteria, patients with ADR related to clinical neurological practice within the period described were selected. They had to fulfill the definitions described in the ATC code, ICD-10 and the classification of psychotropic drugs as described below (WHO/Centre for Drug Statistics Methodology, 2021, WHO, 2010, Bolaños, 2016). Patients under 18 years old, patients with drug intoxications (4 patients) and patients from whom no data of the drug that produced ADR was described (3 patients) were excluded from this category.

Once the screening was done, patients were assigned within two groups; Sys-D and CNS-D. 
The patient information leaflet of each drug, were analyzed according to local regulatory agencies to determine if the adverse reaction had been previously described (National Drug Formulary-VNM, s.f.). In order to determine the causality of the reactions, the Naranjo Score and the classification of the categories according to the Uppsala Monitoring Centre were used (WHO, 2001; Naranjo et al. 1981).

\section{Definition of variables}

- NPhVG: Science which tries to collect, watch, investigate and assess adverse effects at the level of the nervous system by systemic drugs, or the drugs with activity in the nervous system that produce adverse effects.

- $A D R$ : Harmful and unwanted reaction that occurs after the administration of a drug, at doses commonly used in the human species, to prevent, diagnose or treat a disease, or to modify any biological function (WHO/The Uppsala Monitoring Centre, 2001; Regulation No. 5358, 2012).

- $C N S-D$ : The primary mechanism of action is the nervous system. For example: antiepileptics, psycholeptics, and psychoanaleptics.

- Sys-D: Main mechanism of action outside the nervous system. For example: antibiotics, antineoplastics, immunosuppressants, antiarrhythmics, diuretics, etc.

- Neurological ADR (ADR-N): Adverse effect that causes neurological symptoms or diseases.

- Systemic ADR (ADR-S): Adverse effect in any system or organ, except for the nervous system.

- Re exposition: The assessment related to causality, when the reaction or event reappears after the administration of a suspicious medicine (Regulation No. 5358, 2012).

- Categories of causalities according to Uppsala Monitoring Centre: Defined, Probable, Possible, Not related, Conditioned, Dismissed (WHO/The Uppsala Monitoring Centre, 2001).

- Scoring according to Naranjo Algorithm (AIN) (Naranjo et al. 1981).

- Classification of adverse reactions by Edward and Aronson (2000).

- Serious Adverse Reaction (SAR): It is considered serious any ADR that causes death or death threat, requires or extends hospitalization, produces congenital anomalies or leaves a permanent effect or consequence (WHO/The Uppsala Monitoring Centre, 2001; Bignone \& Schiaffino, 2016).

- Unexpected Adverse Reaction (UAR): It is an adverse reaction which nature or intensity is not consistent with the local information, the commercialization authorization or it is not expected due to the pharmacological characteristics of the medication. The predominant element in this case is that the effect must be unknown (WHO/The Uppsala Monitoring Centre, 2001). 
- Psychotropic drugs classification according to Delay and Deniker (cite by Bolaños, 2016).

- Anatomy, Treatment and Chemical classification (ATC code): System of coding medicines and drugs depending on the pharmacological effect, its therapeutic instructions and its chemical structure (WHO/Centre for Drug Statistics Methodology, 2021).

- International Classification of Illnesses, tenth version (ICI-10): It determines the classification and coding of illnesses and a great variety of signs, symptoms, uncommon findings, reports, social circumstances and external causes of damage and/or illness (WHO/Centre for Drug Statistics Methodology, 2021).

- Evolution Timing: timing in days from the administration of the molecule and the ADR.

- Time from the beginning of $A D R$ and the discontinuing of the drug: time in days from the beginning of ADR and the discontinuing of the molecule.

- Days of ADR: Time in days from the beginning to the end of ADR.

- Drug Poisoning (DP): Harmful physiological effects due to the exposure to pharmaceutical products, illegal drugs or chemical substances (Bolaños, 2016).

- Polypharmacy: Simultaneous consumption of five drugs or more (Rattagan et al., 2106).

\section{Statistical analysis}

Descriptive statistical and non-parametric testing were done using the Mann-Whitney Test to compare quantitative variables between two groups and the Chi Cuadrado Test, with Fisher corrections, for dichotomous variables. The SPSS statistical package was used considering significant statistical values with $p<0.05$. This study was carried out according to the Good Clinic Practice of ICH, 1964 last revision of Helsinki Declaration. Due to the nature of the study, the explicit approval of an ethical committee of scientific research was not required, though the confidentiality of the data used was scrupulously respected in every moment in such a way that the anonymity of the patients was guaranteed. For that reason, the data has been used only once on the database, without any direct identification of the patients involved.

\section{RESULTS}

\section{Total sample of ADRs}

Out of 64 patients included, $55(38 \%)(n=36)$ were men and 44.81\% $(n=29)$ were women with a median age of $62.73(\mathrm{DS} \pm 17.30)$ showing an average of 63 years old (ranging 25 96). In total there were $71 \mathrm{ADR}$ with seven patients having more than two ADRs.

Concerning hospitalization, the average number of admission days was 21.6 (DS 25.06), with a median of 13 days (ranging 1-135). ADR caused the hospitalization in 53.52\% $(n=33)$ of the sample. ADR occurred during hospitalization in $29.57 \%(n=21)$ while 25.35\% $(n=18)$ extended it. Regarding the evolution timing, the average was 5.36 (DS $=7.54$ ) and the median was 3 days (ranging $0-30$ ). $67.6 \%$ of the sample showed serious 
ADR, 12.67\% $(n=9)$ showed an unexpected ADR, while 8.45\% $(n=6)$ had a re exposition and $40.84 \%(n=29)$ was under polypharmacy (Table 1$)$.

TABLE 1.

Demographic and descriptive variables of the sample.

\begin{tabular}{|c|c|c|c|c|}
\hline & Total sample $(n=71)$ & CNS-D $(n=45)$ & Sys-D $(n=26)$ & $\mathrm{p}$ \\
\hline \multicolumn{5}{|c|}{ Gender } \\
\hline Female $n(\%)$ & $32(45.07 \%)$ & $22(48.9 \%)$ & $16(61.5 \%)$ & \multirow{2}{*}{0.30} \\
\hline Male $n(\%)$ & $39(54.9 \%)$ & $23(51.1 \%)$ & $10(38.5 \%)$ & \\
\hline Age & $62.73(\mathrm{SD} 17.89)$ & $62.24(\mathrm{SD} 17.75)$ & 63.88 (SD 16.79) & 0.70 \\
\hline \multicolumn{5}{|c|}{ Hospitalization } \\
\hline Hospitalization days & $21.60(\mathrm{SD} 25.06)$ & $18.02(\mathrm{SD} 22.47)$ & $26.46(\mathrm{SD} 28.86)$ & 0.17 \\
\hline Reason for admission $n(\%)$ & $33(53.52 \%)$ & $26(57.8 \%)$ & $7(38.9 \%)$ & 0.17 \\
\hline During hospitalization $n(\%)$ & $21(29.57 \%)$ & $10(22.2 \%)$ & $11(77.8 \%)$ & 0.07 \\
\hline Extended hospitalization $n(\%)$ & $18(25.35 \%)$ & $8(17.8 \%)$ & $10(38.5 \%)$ & 0.05 \\
\hline Time of evolution (days)* & $5.36(\mathrm{SD} 7.54)$ & 4.5 (SD 5.89) & $5.93(\mathrm{SD} 8.63)$ & 0.65 \\
\hline Severe ADR $n(\%)$ & $48(67.60 \%)$ & $31(68.9 \%)$ & $17(65.4 \%)$ & 0.76 \\
\hline Unexpected ADR $n(\%)$ & $9(12.67 \%)$ & $6(13.3 \%)$ & $11.50 \%$ & 0.87 \\
\hline Re exposition $n(\%)$ & $6(8.45 \%)$ & $4(8.9 \%)$ & $2(7.7 \%)$ & 0.86 \\
\hline Notification ANMAT $n(\%)$ & $2(2.81 \%)$ & $0(0 \%)$ & $2(7.7 \%)$ & 0.05 \\
\hline Polypharmacy $n(\%)$ & $29(40.84 \%)$ & $20(44.4 \%)$ & $9(34.6 \%)$ & 0.41 \\
\hline
\end{tabular}

Data expressed as median and SD (Standard Deviation); CNS-D: Central Nervous System Drugs; Sys-D: Systemic Drugs. "Time of evolution: Timing in days from the administration of the molecule and the ADR.

\section{ADRs developed by drugs used for neurological diseases (CNS-D)}

$48.9 \%(n=22)$ of CNS-D were female patients, whereas $51.1 \%(n=23)$ were male patients. The median age was 62.2 years (SD 17.8). The average admission days for this group was 18 days (SD 22.47), with a median of 11 days (range 2-126). The CNS-D group motivated the hospitalization in $57.8 \%(n=26)$. An ADR was produced during hospitalization in $22.2 \%(n=10)$ and it extended the hospitalization in $17.8 \%(n=8)$ of the sample. Within the CNS-D group that most frequently produced ADR, the ones which stood out were antiepileptics (AED) (Figure 1), and between those, diphenylhydantoin (DFH) and carbamazepine (CBZ) (Figure 2) were prominent. Psycholeptics represented 44\% $(n=20)$ being lithium the most frequent $(n=9)$. Concerning the time of evolution of the ADR, the median was 4.5 days (SD 5.89). 68.9\% $(n=31)$ showed serious ADR. $13.3 \%(n=6)$ showed unexpected ADR while $8.9 \%(n=4)$ had a re exposition to the molecule. $44.4 \%$ $(n=20)$ showed polypharmacy at the time of hospitalization (Table 1$)$. 


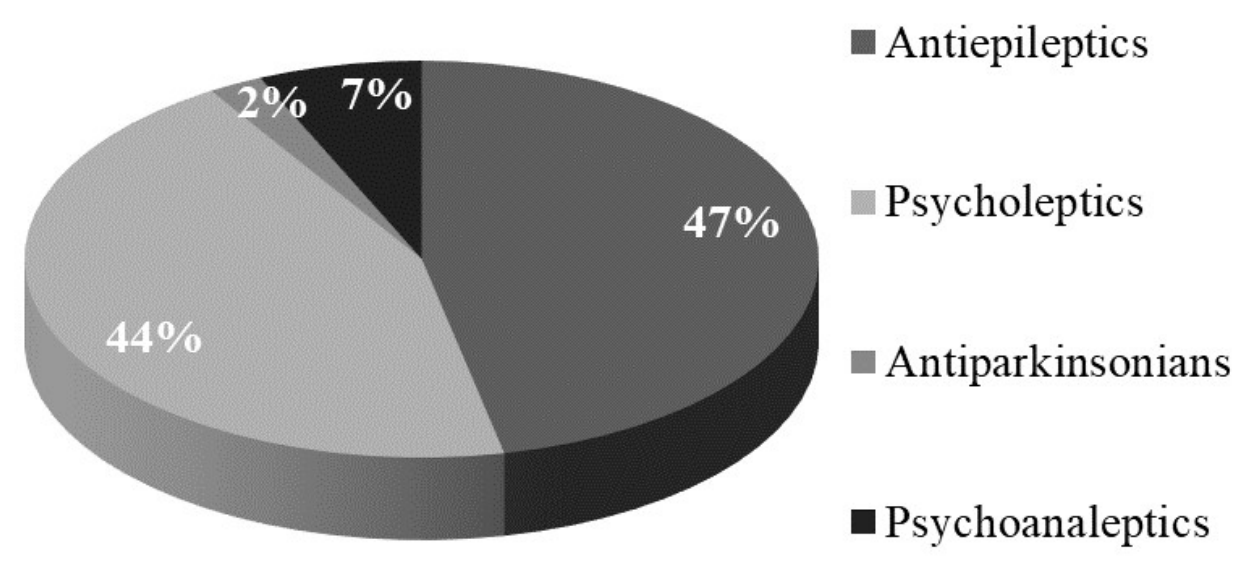

Figure 1. Neurological drugs that caused ADR $(n=45)$.

Source: Authors.

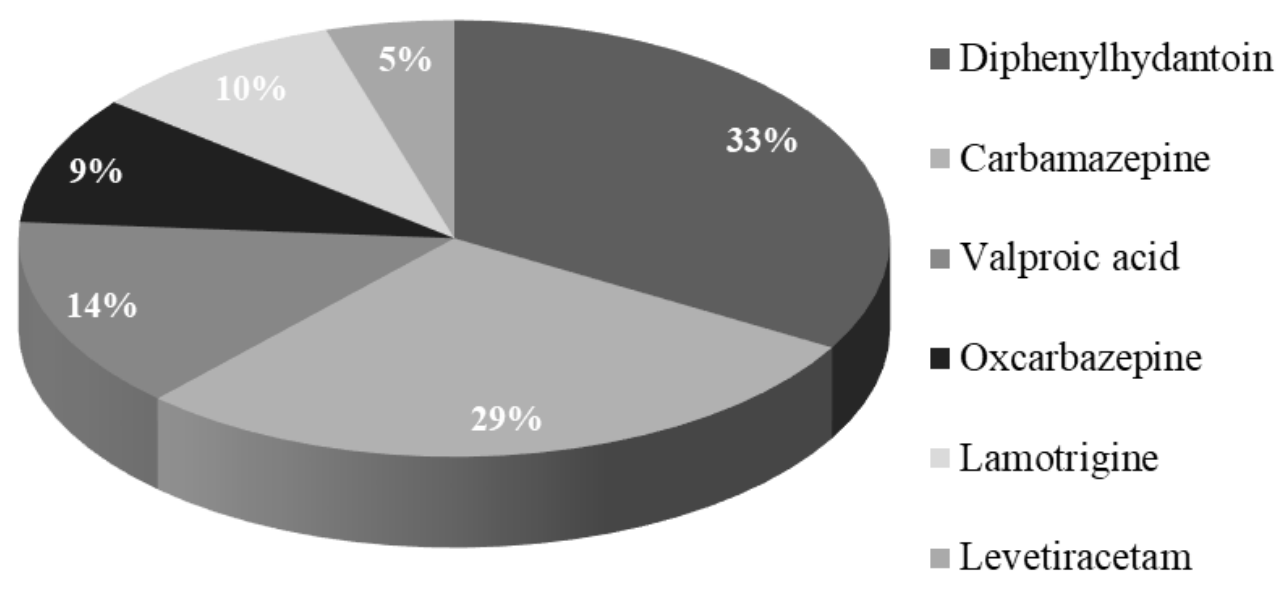

Figure 2. Antiepileptic drugs that caused ADRs $(n=21)$.

Source: Authors.

According to the score of Naranjo Algorithm, 73.3\% $(n=33)$ showed a probable cause of ADR, while $26.7 \%(n=12)$ were possible. The median of the score was 5.22 points (SD 1,4). (Table 2).

TABLE 2.

Imputability variables and types of ADRs.

\begin{tabular}{|c|c|c|c|c|}
\hline & Total sample $(\mathrm{n}=71)$ & CNS-D $(n=45)$ & Sys-D $(n=26)$ & $\mathrm{p}$ \\
\hline \multicolumn{5}{|c|}{ Naranjo Algorithm } \\
\hline \multicolumn{4}{|c|}{ Category } & \multirow{4}{*}{0.003} \\
\hline Confirmed & $0 \%$ & $0 \%$ & $0 \%$ & \\
\hline Probable & $43(60.6 \%)$ & $33(73.3 \%)$ & $10(38.5 \%)$ & \\
\hline Possible & $28(39.4 \%)$ & $12(26.7 \%)$ & $16(61.5 \%)$ & \\
\hline Score & $4.90(\mathrm{SD} \pm 1.50)$ & $5.22(\mathrm{SD} \pm 1.49)$ & $4.34(\mathrm{SD} \pm 1.38)$ & 0.017 \\
\hline \multicolumn{5}{|c|}{ ADR type } \\
\hline A & $45(63.4 \%)$ & $33(73.3 \%)$ & $12(46.2 \%)$ & \multirow{2}{*}{0.022} \\
\hline B & $26(36.6 \%)$ & $12(26.7 \%)$ & $14(53.8 \%)$ & \\
\hline
\end{tabular}

Source: Authors. 
It is important to mention the case of a patient who was prescribed levetiracetam (LVT) due to a focal epilepsy. After a few months, he developed behavior disorders which improved once the medicine was stopped. Another patient showed rhabdomyolysis after the use of DFH. And another one showed hyperammonemia after using valproic acid.

\section{ADR caused by systemic drugs}

61.5\% $(n=16)$ of Sys-D group were females whereas $38.5 \%(n=10)$ were males. The median age of the sample was 63.88 years $(\mathrm{SD} \pm 16.8$ ) with a median of 60 years (range 28-90). The average days of admission for this group was 26.5 days ( $\mathrm{SD} \pm 28.86$ ) showing a median of 18 days (1-135). The Sys-D group motivated hospitalization in $38.9 \%(n=7)$. ADRs were produced during hospitalization in $77.8 \%(n=11)$ and it extended hospitalization in $38.5 \%(n=10)$ of the sample. Within the most frequent Sys-D group, antiarrhythmic and antibiotics stood out with 34\% $(n=9)$ for both groups (Figure 3).

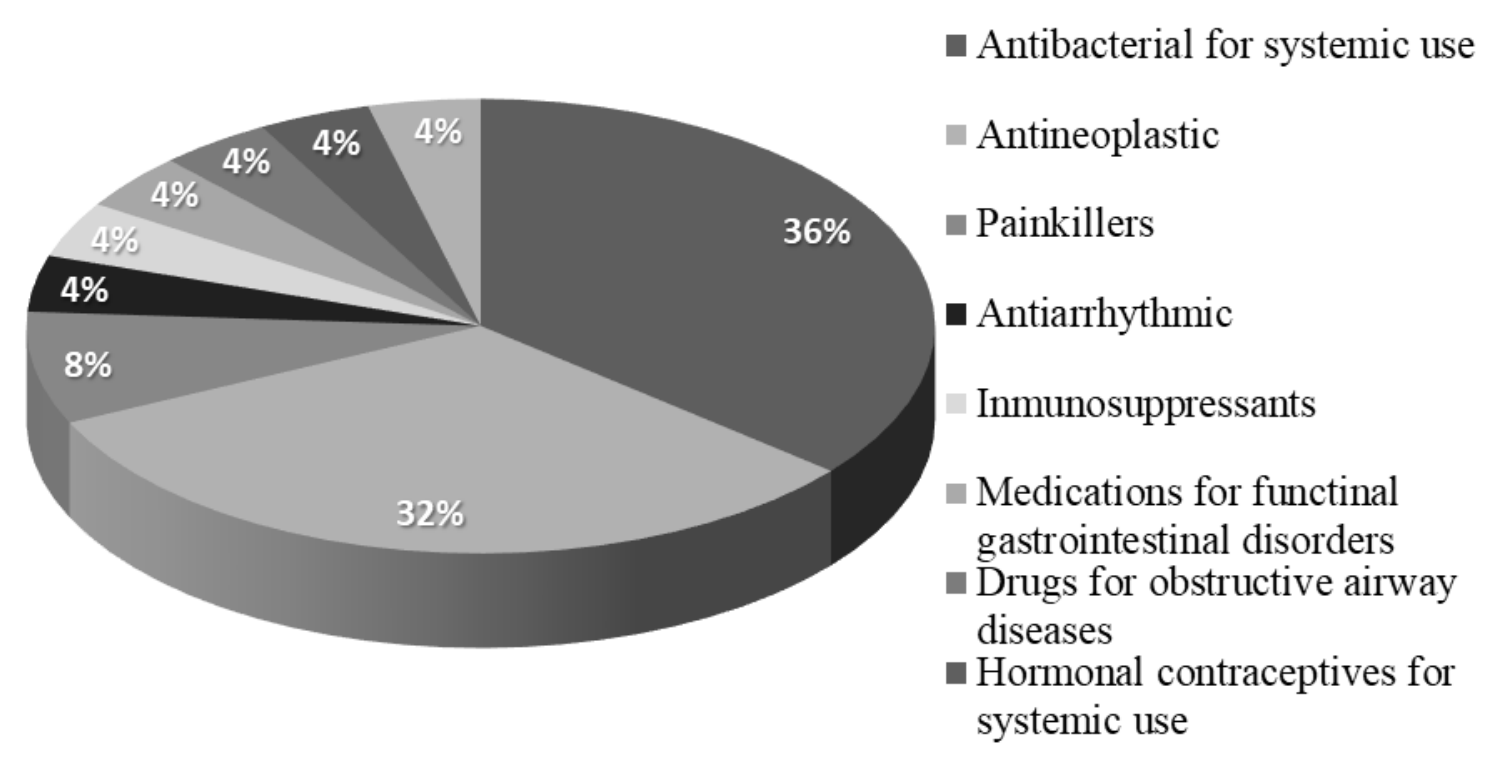

Figure 3. Systemic drugs that caused ADRs $(n=26)$.

Source: Authors.

Concerning the time of evolution of ADRs, the median was 5.93 days (SD = 8.63). 65.4\% $(n=17)$ showed serious ADRs. $11.5 \%(n=3)$ showed unexpected ADR whereas $7.7 \%(n=2)$ had re exposition to the molecule. $34.6 \%(n=9)$ showed polypharmacy at the time of hospitalization (Table 1).

According to the score of Naranjo Algorithm, 38.5\% $(n=10)$ of the sample showed a probable causality of ADR while $61.5 \%(n=16)$ were possible. The median of the score was 4.34 days $(\mathrm{SD} \pm 1.38)$ (Table 2$)$.

In this group, a patient in treatment with pazopanib (tyrosine kinase inhibitor) had Posterior Reversible Encephalopathy Syndrome (PRES). Another patient with lupus (LES) showed aseptic meningitis by Trimethoprim-Sulphametoxazol (TMS) with a Physicochemical of Cerebrospinal Fluid (CSF) of 1000 cells Predominantly Polymorphonuclear $(\mathrm{PMN})$ requiring an exhaustive analysis of differential diagnoses. In this particular case the diagnostic key was the re exposition to the drug with the same symptoms and their 
disappearance hours later after its suspension. Other cases of encephalopathy induced in two patients by axitinib (tyrosine kinase inhibitor) and tacrolimus are mentioned, with improvement after the withdrawal of the drug. Also, a case of cerebritis secondary to cytarabine is highlighted.

\section{Comparative analysis between CNS-D and Sys-D}

It was observed that in Sys-D group hospitalization was extended in $38.5 \%(n=10)$ compared to the CNS-D group, with $17.8 \%(n=8)(p=0.053)$. Other comparisons can be seen in Table 1 without any significant statistics.

According to Edward and Aronson adverse reactions classification, it was seen that the CNS-D group presented a higher percentage of ADR type A $(73.3 \% ; n=33)$ and the Sys-D group had a higher frequency of ADR type B $(53.8 \% ; n=14)$ with a $p=0.0022$.

\section{Discussion}

One of the main aims of PhVG is to report the ADRs due to its implications in public health (Bignone \& Schiaffino, 2016; Ponte et al., 2013). Polypharmacy and ADRs cause a higher number of hospitalizations, extending the time of hospital stay thus generating a higher demand of supplies which produce an economic impact (Ponte et al., 2013; Chaio et al., 2013). There are a few publications on this subject especially on neurological ADRs.

In Neuro-Pharmacovigilance there are different scenarios where the neurologist finds himself in everyday practice. This study allows to describe these different scenarios through the analysis of the characteristics of ADRs. On one hand, ADRs produced by CNS$\mathrm{D}$ which are the ones the neurologist finds constantly allowing a higher level of suspicion. According to Ponte et al and Chaio et al Neuropsychiatric ADRs were 118 (4.87\%) and 9 (8\%) respectively (Ponte et al., 2013; Chaio et al., 2013). In the current study antipsychotic and antiepileptic drugs produced ADRs with higher frequency in the CNS-D group.

On the other hand, most of the Sys-D showed neurotoxicity, like antibiotics or antineoplastic drugs. These ADRs are a diagnosis challenge because they have a low suspicion, or they could be confused with other neurological diseases. Thus, this highlights the different neurological diagnosis without any etiology that has a time relation with consuming a medication in a short, medium or long period.

It is important to emphasize the imputability of ADRs, considering the time between the drug administration and the event, the medical or pharmacological plausibility and the probability or exclusion of other causes (WHO/ The Uppsala Monitoring Centre, 2001). Therefore, a comparison was done based on the Naranjo Score between ADRs produced by CNS-D and Sys-D. It was observed that Sys-D group showed a high percentage of ADRs in the "possible" category. On the contrary, CNS-D group showed a high percentage in the "probable" category, indicating a significant statistic. Consequently, it is possible to find a major difficulty in making an ADR diagnose by systemic drugs because there are distractive elements. The view is even more complex to determine the timing between the drug and the event in a large number of patients due to the scarce knowledge of the neurological ADR of new pharmacological therapies. 
As above mentioned, when comparing CNS-D and Sys-D groups on the basis of the ADR type according to Edward and Aronson classification, it was observed that the first group showed a high percentage of ADR type A and Sys-D group has a high frequency of ADR type B (Edward \& Aronson, 2000). This finding reinforces the concept of the diagnosis challenge of neurological ADR produced by Sys-D because they are uncommon, they do not show any relationship with the mechanism of action in some cases and they show unpredictable mechanisms of action in others.

On this scenario, health professionals should be encouraged to increase the number of notifications of ADRs in order to gain knowledge on ADR. The reduced number of publications plus the underreported notifications, generate limited statistical data, delaying the detection of signals and causing underestimation of the real magnitude of the problem. Hence the unawareness of the medicine during its commercialization stage.

There are multiple reasons that influence the lack of notifications, like underdiagnosis, fear of reprisals, scarce information on PhVG, short time, among others (Grill \& Maganti, 2011; Bolaños, 2016). Regarding underdiagnoses, it is possible that ADRs are not considered as a cause of a disease.

The population with highest risks of developing ADRs is on the age extremes (newborns and the elderly ones) and polypharmacy patients (Ponte et al., 2013). Firstly, ADRs could be originated from changes in pharmacokinetic and pharmacodynamics (Rattagan et al. 2016). Secondly, elderly patients are exposed to polypharmacy due to the high prevalence of chronic disease. Our research is in accordance with the current literature, which is, a high level of polypharmacy thus causing an increase in the probability of showing an ADR.

The limitations of our data include the observational retrospective nature, so that the scarce availability of demographic data and the exposition time did not allow to have a higher number for statistical analysis. Only hospitalized patients were included, therefore, a great number of patients were not included in the sample which explains its limited size. For this purpose, patients who do not show serious ADRs are not requested neurological consultant and not all hospitalized patients are assessed by this specialty.

Considering the major assets of the current research and the few ones published in Argentina, this might be the first one which has a detailed analysis of neurological diseases (Martino et al., 2019).

Therefore, it is important to make a proper statement to the authorities to have national data to take sanitary measures. Finally, by excluding drug intoxications uncertainty was avoided at the time of analyzing different ADRs.

\section{Conclusions}

In the diagnostic algorithm of a patient who shows neurological symptoms, it is convenient to suspect of an ADR as a possible etiology. It is the only way to avoid an exhaustive and unnecessary diagnostic research as well as empiric treatments that could be unjustified. In many cases, diagnosis and treatment could be delayed because medication might not be considered as a cause. 
There are ADRs seemingly rare because they are less frequent. However, they are already described in the national prospects. Therefore, they are not rare themselves but unknown to the health professional. It could be useful to check the drug prospect on a regular basis, especially in cases where there has been a meaningful time relation between the drug and the beginning of the event.

\section{ACKNOWLEDGEMENTS}

I would like to thank Victoria Sanchez de Paz, Anna Fernandez, Damián Lerman, Inés Bignone and Roberto Diez who have been supportive of my career goals.

\section{REFERENCES}

Bignone, I. y Schiaffino, S. (2016). Manual de Buenas Prácticas de Farmacovigilancia. [1a ed.]. Buenos Aires: Ediciones Farmacológicas.

Bolaños, R. (Coord.). (2016). Psicotrópicos y estupefacientes. Buenos Aires: Administración Nacional de Medicamentos, Alimentos y Tecnología Médica. Buenos Aires: ANMAT. Recuperado de http://www.anmat.gov.ar/ssce/Libro-psicotropicos-estupefacientes.pdf

Chaio, S.; Toibaro, J.; Valicenti, P. \& Saidón, P. (2013). Reacciones adversas medicamentosas y errores de prescripción: Morbi-Mortalidad. Medicina, 73(2), 111-118. Recuperadode

http://www.scielo.org.ar/pdf/medba/v73n2/v73n2a03.pdf

Edwards, R. \& Aronson, J. (2000). Adverse drug reactions: definitions, diagnosis, and management. Lancet, 356(9237), 1255-1259.

https://doi.org/10.1016/S0140-6736(00)02799-9

Grill, M. F. \& Maganti, R. K. (2011). Neurotoxic effects associated with antibiotic use: management considerations. British Journal of Clinical Pharmacology, 72(3), 381393.

https://doi.org/10.1111/j.1365-2125.2011.03991.x

Lazarou, J.; Pomeranz, B. \& Corey P. (1998). Incidence of adverse drug reactions in hospitalized patients. A meta-analysis of prospective studies. JAMA, 279(15), 1200-1205. https://doi.org/10.1001/jama.279.15.1200

Martino, G.; Rojas, G.; Sánchez, M. P.; Isaa, S.; Bres, M.; Camino, M. V..; Merchán, X.; Aldinio, V.; Parisi, V.; Persi, G.; Pereira, N. \& Gatto, E. (2019). Seguridad de fármacos antineoplásicos e inmunomoduladores aplicados a la neurología. Neurolargía Argentina, 11(3), 136-144. https://doi.org/10.1016/j.neuarg.2019.03.001

Naranjo, C. A.; Busto, U.; Sellers, E. M.; Sandor, P.; Ruiz, I.; Roberts E.A.; Janecek, E.; Domecq C. \& Greenblatt, D. J. (1981). A method for estimating the probability of adverse drug reactions. Clinical Pharmacology and Therapeutics, 30(2), 239-245. https://doi.org/10.1038/clpt.1981.154 
Orta, I. A.; Garcia, O.; Triolet, A. T.; Gómez, C. \& Ruiz, K. (2008). Reacciones adversas a medicamentos en una unidad de terapia intensiva. Revista Electrónica de Biomedicina, 2, 10-18. Disponible en http://biomed.uninet.edu/2008/n2/alfonso.html

Ponte, M. L.; Ragusa, M.; Armenteros, C. \& Wachs, A. (2013). Relevancia de la farmacovigilancia hospitalaria en la práctica médica actual. Medicina (Buenos Aires), 73(1), 35-38. Recuperado de

http://www.scielo.org.ar/pdf/medba/v73n1/v73n1a07.pdf

Rattagan, M. L.; Lisei, D.; Rojas, J. G.; Persi, G.; Parisi, V.; López, M.; Da Prat, G.; Bres M. \& Gatto, E. (2016). Uso de psicotrópicos y carga sedativa en pacientes adultos con y sin demencia. Vertex, XXVII(129), 332-338. Disponible en

http://www.editorialpolemos.com.ar/vertex129.php

República de Argentina. Ministerio de Salud. (10 de septiembre de 2012). Buenas practicas de farmacovigilancia. [Disposición $n^{\circ}$ 5358]. Boletín Nacional: 23-Ene-2013. Disponible en

https://ww w.argentina.gob.ar/normativa/nacional/disposici\% C $3 \% \mathrm{~B}$ 3n-5358-2012-207727

Rojas, G.; Demey, I. \& Arizaga, R. L. (2013). Medicamentos utilizados para trastornos cognitivos. Análisis de un millón y medio de prescripciones en la Argentina. Medicina (Buenos Aires), 73(3), 213-223. Recuperado de http://www.scielo.org.ar/pdf/medba/v73n3/v73n3a03.pdf

Sauro, K. M.; Quan, H.; Sikdar, K.; Faris, P. \& Jette, N. (2017). Hospital safety among neurologic patients: A population-based cohort study of adverse events. Neurology, 89(3), 284-290.

https://doi.org/10.1212/wnl.0000000000004111

VNM. (s.f.). Vademecum Nacional de Medicamentos. Buenos Aires: ANMAT. Disponible en

http://anmatvademecum.servicios.pami.org.ar/index.html

WHO. (2010). International Statistical Classification of Diseases and Related Health Problems 10th Revision. Sweden: CDC. Available:

http://apps.who.int/classifications/icd10/browse/2010/en

WHO. (1999). Perspectivas políticas de la OMS sobre medicamentos: La farmacovigilancia: garantía de seguridad en el uso de los medicamentos. [WHO/EDM/QSM/99.1]. Ginebra: OMS. Disponible en https://apps.who.int/iris/handle/10665/65892

WHO/Centre for Drug Statistics Methodology. (2021). The Anatomical Therapeutic Chemical (ATC) classification system. [Online]. Available:

https://www.whocc.no/atc_ddd_index/

WHO. The Uppsala Monitoring Centre. (2001). Vigilancia de la seguridad de los medicamentos. Guía para la instalación y puesta en funcionamiento de un Centro de Farmacovigilancia. Sweden: UMC. Available:

http://www.essalud.gob.pe/ietsi/pdfs/informacion_tecnica/OMS_guia_farmacovigilancia.pdf 